\title{
Clearing up the confusion: The results of two pilot studies of antipsychotics for ICU delirium.
}

\author{
Zaher Qassem ${ }^{1}$ and Eric B Milbrandt*2 \\ University of Pittsburgh Department of Critical Care Medicine: Evidence-Based Medicine Journal Club, edited by Eric B Milbrandt
}

\begin{abstract}
Expanded Abstracts Citation \#1

Girard TD, Pandharipande PP, Carson SS, Schmidt GA, Wright PE, Canonico AE, Pun BT, Thompson JL, Shintani AK, Meltzer HY, Bernard GR, Dittus RS, Ely EW: Feasibility, efficacy, and safety of antipsychotics for intensive care unit delirium: the MIND randomized, placebocontrolled trial. Crit Care Med 2010, 38:428-437 [1].
\end{abstract}

\section{Background}

Given the lack of compelling evidence supporting the use of antipsychotics for delirium in critically ill patients and the potential adverse effects associated with these medications, placebo-controlled clinical trials are greatly needed.

\section{Methods \\ Objective: To demonstrate the feasibility of a placebo- controlled trial of antipsychotics for delirium in the intensive care unit and to test the hypothesis that antipsychotics would improve days alive without delirium or coma.}

Design: Randomized, double-blind, placebo-controlled trial.

Setting: Six tertiary care medical centers in the US.

Subjects: One hundred one mechanically ventilated medical and surgical intensive care unit patients.

Intervention: Patients were randomly assigned to receive haloperidol or ziprasidone or placebo every 6 hrs for up to 14 days. Twice each day, frequency of study drug administration was adjusted according to delirium status, level of sedation, and side effects.

Outcomes: The primary end point was the number of days patients were alive without delirium or coma. Secondary efficacy end points included daily delirium

\footnotetext{
*Correspondence: emilbrandt@hotmail.com

${ }^{2}$ Assistant Professor, Department of Critical Care Medicine, University of Pittsburgh

School of Medicine, Pittsburgh, Pennsylvania, USA

Full list of author information is available at the end of the article
}

risk, duration of delirium, duration of coma, the number of days patients were alive and breathing without assistance during the 21-day study period (ventilator-free days), time to ICU and hospital discharge, and all-cause 21-day survival.

\section{Results}

During the 21-day study period, patients in the haloperidol group spent a similar number days alive without delirium or coma (median [interquartile range], 14.0 [6.0-18.0] days) as did patients in the ziprasidone (15.0 [9.1-18.0] days) and placebo groups (12.5 [1.2$17.2]$ days; $p=0.66)$. No differences were found in secondary clinical outcomes, including ventilator-free days $(\mathrm{p}=.25)$, hospital length of stay $(\mathrm{p}=.68)$, and mortality $(\mathrm{p}=.81)$. Ten $(29 \%)$ patients in the haloperidol group reported symptoms consistent with akathisia, compared with six $(20 \%)$ patients in the ziprasidone group and seven $(19 \%)$ patients in the placebo group $(\mathrm{p}=.60)$, and a global measure of extrapyramidal symptoms was similar between treatment groups $(\mathrm{p}=.46)$.

\section{Conclusions}

A randomized, placebo-controlled trial of antipsychotics for delirium in mechanically ventilated intensive care unit patients is feasible. Treatment with antipsychotics in this limited pilot trial did not improve the number of days alive without delirium or coma, nor did it increase adverse outcomes. Thus, a large trial is needed to determine whether use of antipsychotics for intensive care unit delirium is appropriate.

\section{Citation \#2}

Devlin JW, Roberts RJ, Fong JJ, Skrobik Y, Riker RR, Hill NS, Robbins T, Garpestad E: Efficacy and safety of quetiapine in critically ill patients with delirium: a prospective, multicenter, randomized, double-blind, placebo-controlled pilot study. Crit Care Med 2010, 38:419-427 [2] .

\section{Background}

To date, there are no published double-blind, randomized, placebo-controlled trials to establish the efficacy or 
safety of any antipsychotic medication in the management of delirium in the ICU.

\section{Methods \\ Objective: To compare the efficacy and safety of scheduled quetiapine to placebo for the treatment of delirium in critically ill patients requiring as-needed haloperidol. \\ Design: Prospective, randomized, double-blind, placebo- controlled study. \\ Setting: Three academic medical centers in the US and Canada. \\ Subjects: Thirty-six adult intensive care unit patients with delirium (Intensive Care Delirium Screening Checklist score $>=4$ ), tolerating enteral nutrition, and without a complicating neurologic condition. \\ Intervention: Patients were randomized to receive quetiapine $50 \mathrm{mg}$ every $12 \mathrm{hrs}$ or placebo. Quetiapine was increased every $24 \mathrm{hrs}$ (50 to 100 to 150 to $200 \mathrm{mg}$ every $12 \mathrm{hrs}$ ) if more than one dose of haloperidol was given in the previous 24 hrs. Study drug was continued until the intensive care unit team discontinued it because of delirium resolution, therapy $>=10$ days, or intensive care unit discharge. \\ Outcomes: The primary end point was time to first resolu- tion of delirium. Secondary outcomes included duration of mechanical ventilation, ICU and hospital length of stay, hospital mortality, and discharge disposition. Measures of safety included total number of adverse and serious adverse events related to study drug, incidence of extrapyramidal symptoms, and episodes of QTc interval prolongation.}

\section{Results}

Baseline characteristics were similar between the quetiapine $(\mathrm{n}=18)$ and placebo $(\mathrm{n}=18)$ groups. Quetiapine was associated with a shorter time to first resolution of delirium $[1.0$ (interquartile range $[\mathrm{IQR}], 0.5-3.0$ ) vs. 4.5 days (IQR, 2.0-7.0; $\mathrm{p}=.001$ )], a reduced duration of delirium [36 (IQR, 12-87) vs. 120 hrs (IQR, 60-195; $\mathrm{p}=.006)]$, and less agitation (Sedation-Agitation Scale score > =5) [6 (IQR, 0-38) vs. 36 hrs (IQR, 11-66; p =.02)]. Whereas mortality (11\% quetiapine vs. $17 \%$ ) and intensive care unit length of stay (16 quetiapine vs. 16 days) were similar, subjects treated with quetiapine were more likely to be discharged home or to rehabilitation (89\% quetiapine vs. $56 \% ; \mathrm{p}=.06$ ). Subjects treated with quetiapine required fewer days of as-needed haloperidol [3 [(IQR, 2-4)] vs. 4 days (IQR, 3-8; $\mathrm{p}=.05)$ ]. Whereas the incidence of QTC prolongation and extrapyramidal symptoms was similar between groups, more somnolence was observed with quetiapine ( $22 \%$ vs. $11 \%$; $\mathrm{p}=.66)$.

\section{Conclusions}

Quetiapine added to as-needed haloperidol results in faster delirium resolution, less agitation, and a greater rate of transfer to home or rehabilitation. Future studies should evaluate the effect of quetiapine on mortality, resource utilization, post-intensive care unit cognition, and dependency after discharge in a broader group of patients.

\section{Commentary}

Delirium is an acute disturbance in consciousness and cognition that fluctuates in severity. Rather than a passing phase, delirium is now recognized as acute brain dysfunction and is associated with increased length of stay, cost, and mortality. Delirium is very common in the intensive care unit (ICU), occurring in $20-80 \%$ of patients, with the highest proportions seen in mechanically ventilated patients. There is no US Food and Drug Administration approved treatment for delirium, though national guidelines recommended haloperidol as the drug of choice [3]. More recently, atypical antipsychotics have also been used. Observational data and one small randomized controlled trial in patients with hip fracture suggest improved outcomes with antipsychotics [4,5], yet until recently there were no placebo-controlled clinical trials in ICU patients to determine whether these drugs improve clinical outcomes or merely treat symptoms.

The two pilot studies reviewed in this critique provide the first randomized, placebo-controlled evidence for the pharmacologic treatment of ICU delirium [1,2]. In the first study, Girard and colleagues compared haloperidol, ziprasidone, and placebo in the treatment of delirium in 101 adult mechanically ventilated medical and surgical ICU patients [1]. Twice daily the frequency of study drug administration was adjusted according to delirium status and side effects. The authors found that neither haloperidol nor ziprasidone significantly reduced the duration of delirium compared with placebo. No differences were found in secondary clinical outcomes, including ventilator-free days, hospital length of stay and mortality. The adverse events were similar between the three groups with no events being serious. Ten patients had prolongation of the QTc $>500 \mathrm{msec}$ (haloperidol 5.7\% vs. ziprasidone $16.7 \%$ vs. placebo $8.3 \%, \mathrm{p}=0.31$ ), usually within 48 hours of study drug initiation.

In the second study, Devlin and colleagues compared quetiapine and placebo in the treatment of delirium in 36 adult medical and surgical ICU patients [2]. In this study, quetiapine was increased every 24 hours if more than one dose of haloperidol was given in the previous 24 hours. The authors found that scheduled, dose-escalated quetiapine added to as-needed haloperidol resulted in faster delirium resolution, less agitation, and a trend toward a greater rate of transfer to home or rehabilitation without any differences in mortality. There were no serious study drug-related adverse events. QTc prolongation $>500 \mathrm{msec}$ was more common in placebo subjects $(28 \%$ 
vs. 22\%), though this difference was not significant $(\mathrm{p}=1.0)$.

These two studies are groundbreaking in the area of ICU delirium. Both were well-conducted and used validated and reliable delirium screening tools. In neither study were serious adverse events more common in active treatment groups, suggesting that antipsychotics were safe, at least within these patient populations and within the context of close monitoring for adverse events. Unfortunately, both studies were too small to reliably detect differences in important clinical outcomes, such as mortality or length of stay. This limitation was further amplified by the use of open-label, as-needed antipsychotics if the clinical team considered it necessary, thereby minimizing potential differences between groups.

When encountering delirium in the ICU, it is important to start with modifiable risk factors, such avoiding polypharmacy, promoting sleep hygiene, correcting electrolyte abnormalities, and reorienting frequently, before reaching for drugs. Practically speaking, non-pharmacologic interventions are frequently insufficient. In addition to antipsychotics, emerging research suggests that alternative sedative agents, such as dexmedetomidine $[6,7]$, may be less prone to causing delirium. Furthermore, daily sedation interruption and early physical therapy may also be beneficial [8].

\section{Recommendation}

Taken together, the result of these pilot studies highlight the need for much larger, multicenter, placebo-controlled trials to determine whether continued use of antipsychotics in the ICU is warranted. Though screening for delirium using a validated instrument and treating with haloperidol remain recommended by national guidelines, clinicians should routinely monitor for adverse events, especially QTc prolongation.

\section{Competing interests}

The authors declare that they have no competing interests

\section{Author details}

${ }^{1}$ Clinical Fellow, Department of Critical Care Medicine, University of Pittsburgh School of Medicine, Pittsburgh, Pennsylvania, USA. ${ }^{2}$ Assistant Professor, Department of Critical Care Medicine, University of Pittsburgh School of Medicine, Pittsburgh, Pennsylvania, USA.

Published: 11 August 2010

\section{References}

1. Girard TD, Pandharipande PP, Carson SS, Schmidt GA, Wright PE, Canonico AE, Pun BT, Thompson JL, Shintani AK, Meltzer HY, Bernard GR, Dittus RS, Ely EW: Feasibility, efficacy, and safety of antipsychotics for intensive care unit delirium: the MIND randomized, placebo-controlled trial. Crit Care Med 2010, 38:428-437.

2. Devlin JW, Roberts RJ, Fong JJ, Skrobik Y, Riker RR, Hill NS, Robbins T, Garpestad E: Efficacy and safety of quetiapine in critically ill patients with delirium: a prospective, multicenter, randomized, double-blind, placebocontrolled pilot study. Crit Care Med 2010, 38:419-427.

3. Jacobi J, Fraser GL, Coursin DB, Riker RR, Fontaine D, Wittbrodt ET, Chalfin DB, Masica MF, Bjerke HS, Coplin WM, Crippen DW, Fuchs BD, Kelleher RM, Marik PE, Nasraway SA, Jr., Murray MJ, Peruzzi WT, Lumb PD: Clinical practice guidelines for the sustained use of sedatives and analgesics in the critically ill adult. Crit Care Med 2002, 30:119-141.

4. Milbrandt EB, Kersten A, Kong L, Weissfeld LA, Clermont G, Fink MP, Angus DC: Haloperidol use is associated with lower hospital mortality in mechanically ventilated patients. Crit Care Med 2005, 33:226-229.

5. Kalisvaart KJ, de Jonghe JF, Bogaards MJ, Vreeswijk R, Egberts TC, Burger BJ, Eikelenboom P, van Gool WA: Haloperidol prophylaxis for elderly hipsurgery patients at risk for delirium: a randomized placebo-controlled study. J Am Geriatr Soc 2005, 53:1658-1666.

6. Pandharipande PP, Pun BT, Herr DL, Maze M, Girard TD, Miller RR, Shintani AK, Thompson JL, Jackson JC, Deppen SA, Stiles RA, Dittus RS, Bernard GR, Ely EW: Effect of sedation with dexmedetomidine vs lorazepam on acute brain dysfunction in mechanically ventilated patients: the MENDS randomized controlled trial. JAMA 2007, 298:2644-2653.

7. Riker RR, Shehabi Y, Bokesch PM, Ceraso D, Wisemandle W, Koura F, Whitten P, Margolis BD, Byrne DW, Ely EW, Rocha MG: Dexmedetomidine vs midazolam for sedation of critically ill patients: a randomized trial. JAMA 2009, 301:489-499.

8. Schweickert WD, Pohlman MC, PohIman AS, Nigos C, Pawlik AJ, Esbrook CL, Spears L, Miller M, Franczyk M, Deprizio D, Schmidt GA, Bowman A, Barr R, McCallister KE, Hall JB, Kress JP: Early physical and occupational therapy in mechanically ventilated, critically ill patients: a randomised controlled trial. Lancet 2009, 373:1874-1882.

doi:10.1186/cc9200

Cite this article as: Qassam Z, Milbrandt EB: Clearing up the confusion: The results of two pilot studies of antipsychotics for ICU delirium. Critical Care 2010, 14:316 